\title{
Green Chemicals from D-glucose: Systematic Studies on Catalytic Effects of Inorganic Salts on the Chemo-Selectivity and Yield in Aqueous Solutions
}

\author{
C. B. Rasrendra • I. G. B. N. Makertihartha • \\ S. Adisasmito $\cdot$ H. J. Heeres
}

Published online: 28 May 2010

(C) The Author(s) 2010. This article is published with open access at Springerlink.com

\begin{abstract}
The use of inorganic salts as catalysts for the reactions of D-glucose in aqueous solutions in a batch reactor is reported. The type of salt and effect of reaction time were examined in detail at a fixed salt $(5 \mathrm{mM})$ and $\mathrm{D}-$ glucose concentration $(0.1 \mathrm{M})$ and at a temperature of $140{ }^{\circ} \mathrm{C}$. $\mathrm{Al}(\mathrm{III})$ and $\mathrm{Cr}$ (II) salts gave the highest conversion of D-glucose. Typical reaction products were organic acids like lactic acid, levulinic acid, furanics like hydroxymethylfurfural and insoluble products (humins). The chemoselectivity is a clear function of the type of inorganic salt. For $\mathrm{Al}(\mathrm{III})$, the major water soluble product was lactic acid, for $\mathrm{Zn}$ (II) HMF was formed in the highest yields. A reaction scheme is proposed to explain the observed product compositions.
\end{abstract}

Keywords Inorganic salts - Lewis acids - D-glucose · HMF · Levulinic acid · Lactic acid · Biobased chemicals

\section{Introduction}

Research on green chemicals from renewable resources has boosted over the last decade. The C6-sugars (e.g. D-glucose, D-fructose and D-mannose) in lignocellulosic biomass like wood chips and agricultural residues (e.g. straw, corn stover) are interesting precursors for a broad range of chemicals with high application potential [1,2]. Examples

C. B. Rasrendra · H. J. Heeres ( $\square)$

Department of Chemical Engineering,

University of Groningen, Groningen, The Netherlands

e-mail: h.j.heeres@rug.nl

C. B. Rasrendra - I. G. B. N. Makertihartha - S. Adisasmito Department of Chemical Engineering,

Institut Teknologi Bandung, Bandung, Indonesia of target molecules are organic acids like levulinic acid and lactic acid and furanics like hydroxymethylfurfural (HMF) and 2,5-dimethylfuran.

A well established synthetic methodology for levulinic acid, including HMF as an intermediate product, is the acid catalysed hydrolysis of C6-sugars in water (Scheme 1) $[3,4]$.

Levulinic acid may be obtained in $62 \mathrm{~mol} \%$ yield at $140{ }^{\circ} \mathrm{C}$ in water using sulfuric acid as the catalyst when using D-glucose as the starting material [3]. The intermediate HMF may be obtained in reasonable yields by optimizing the reaction conditions. Recently, organic solvents [5] and ionic liquids [6, 7] were shown to have high potential for these conversions with respect to product selectivity and yield. A wide variety of Bronsted acid catalysts have been tested for these conversions. Examples are homogeneous catalysts like sulfuric acid, hydrochloric acid, phosphoric acid, trifluoroacetic acid [3, 8, 9] and solid acid catalysts like acidic ion exchange resins, zeolites and montmorillonites [10].

Several authors have reported the catalytic effects of metal salts on the dehydration reactions of D-glucose and D-fructose in water. An overview is given in Table 1. In some cases, the combination of Bronsted acids and salts were applied, whereas others only involve the use of inorganic salts. The reactions were carried out at a range of experimental conditions and as such do not provide a consistent picture. The main products are HMF, levulinic acid and/or lactic acid, the yield being a function of process conditions and type of salt.

The reactions performed at temperatures below $150{ }^{\circ} \mathrm{C}$ mainly yield HMF and/or levulinic acid. For instance, Van Dam et al. studied the dehydration of D-fructose using $\mathrm{HCl}$ as the catalyst [11]. The presence of certain salts (e.g. $\mathrm{NaCl}, \mathrm{AlCl}_{3}, \mathrm{CrCl}_{3}$, and $\mathrm{LaCl}_{3}$ ) enhanced the reaction rate 
Scheme 1 Acid-catalysed hydrolysis of D-glucose to levulinic acid

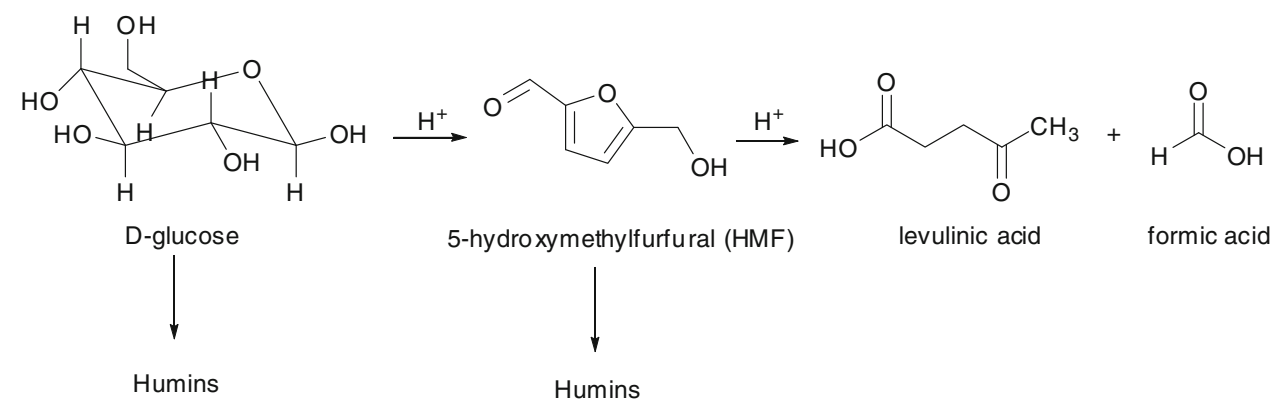

Table 1 C6-sugar conversions using salts as the catalyst

\begin{tabular}{llllll}
\hline No. & Starting material & Catalyst & Conditions & Product (yield) & Ref. \\
\hline 1 & D-fructose $(0.5 \mathrm{M})$ & $\mathrm{HCl}(1 \mathrm{M})$ and $\mathrm{AlCl}_{3}(0.17 \mathrm{M})$ & $88{ }^{\circ} \mathrm{C}, 500 \mathrm{~min}$ & Levulinic acid $(42 \mathrm{~mol} \%), \mathrm{HMF}(15 \mathrm{~mol} \%)$ & {$[11]$} \\
2 & D-glucose $(0.4 \mathrm{M})$ & $\mathrm{HCl}$ in saturated $\mathrm{MgCl}_{2}$ & $3 \mathrm{~h}$ under reflux & Levulinic acid $(61 \mathrm{~mol} \%)$ & {$[12]$} \\
3 & D-fructose $(0.3 \mathrm{M})$ & $\mathrm{DyCl}_{3}(2 \mathrm{mM})$ & $140{ }^{\circ} \mathrm{C}, 120 \mathrm{~min}$ & $\mathrm{HMF}(25 \mathrm{~mol} \%)$ & {$[14]$} \\
4 & D-glucose $(0.3 \mathrm{M})$ & $\mathrm{DyCl}_{3}(2 \mathrm{mM})$ & $140{ }^{\circ} \mathrm{C}, 120 \mathrm{~min}$ & $\mathrm{HMF}(12 \mathrm{~mol} \%)$ & {$[14]$} \\
5 & D-fructose $(0.055 \mathrm{M})$ & $\mathrm{ZnSO}_{4}(400 \mathrm{ppm})$ & $300{ }^{\circ} \mathrm{C}, 250 \mathrm{bar}$ & Lactic acid $(48 \%)^{\mathrm{a}}$ & {$[19]$} \\
6 & D-glucose $(0.07 \mathrm{~g})$ & $\mathrm{CoSO}_{4}(400 \mathrm{ppm})$ & $300{ }^{\circ} \mathrm{C}, 12 \mathrm{~s}$ & Lactic acid (yield: $9.5 \%(\mathrm{~g} / \mathrm{g}))$ & {$[20]$} \\
\hline
\end{tabular}

${ }^{a}$ Selectivity value, defined in $\mathrm{C}-\mathrm{mol} \%$, see Eq. 3

(8\%) and increased the yield of levulinic acid (10\%). Tyrlik et al. discovered that magnesium chloride has a positive effect on the formation of levulinic acid when using D-glucose as substrate and $\mathrm{HCl}$ as the catalyst. The highest yield of levulinic acid was $61 \mathrm{~mol} \%[12,13]$. Serie et al. reported the application of lanthanum salts as active catalysts for converting D-glucose and D-fructose to HMF in water and DMSO $[14,15]$. Krupenskii examined the effects of metal ions such as $\mathrm{Al}^{3+}, \mathrm{Cr}^{3+}, \mathrm{Ti}^{3+}, \mathrm{Cu}^{2+}, \mathrm{Fe}^{3+}$, $\mathrm{Ag}^{+}, \mathrm{Hg}^{2+}$ and $\mathrm{Ce}^{3+}$ on the decomposition of several sugars (D-xylose, L-arabinose, D-glucose, D-galactose, D-mannose) in an acidic medium $\left(T=130-150{ }^{\circ} \mathrm{C}\right)$ [16-18]. A positive effect of the various salts on the dehydration rates of the sugars was observed.

Besides work in aqueous systems at temperatures between 80 and $150{ }^{\circ} \mathrm{C}$, the use of subcritical water at higher temperatures $\left(200-360^{\circ} \mathrm{C}, 250\right.$ bar) has also been explored and was shown to affect the product selectivity considerably. The main product appears lactic acid in this case. For instance, Bicker et al. showed that the presence of $400 \mathrm{ppm}$ of $\mathrm{ZnSO}_{4}$ gave $42 \mathrm{C}$-mol\% of lactic acid $\left(300{ }^{\circ} \mathrm{C}\right.$, 250 bar) [19]. Kong et al. reported the conversion of D-glucose, microcrystalline cellulose and various types of biomass to lactic acid using salts as catalyst in subcritical water [20]. The lactic acid yield for D-glucose was $9.5 \mathrm{wt} \%$ when using $400 \mathrm{ppm} \mathrm{Co}$ (II) as the catalyst at $300{ }^{\circ} \mathrm{C}$ and $120 \mathrm{~s}$. Yan et al. studied the production of lactic acid from D-glucose in water at $300{ }^{\circ} \mathrm{C}$ under basic conditions [21]. Lactic acid was obtained at a yield of $27 \%$ when using $\mathrm{NaOH}$ as the base.
The studies highlighted above indicate that inorganic salts catalyse the conversion of C6-sugars to interesting biobased chemicals. However, systematic studies aiming to identify the most promising salts in aqueous solutions under comparable conditions as well as the role of the salts and insights in reaction pathways are lacking. As part of a larger program to identify novel catalysts for the production of biobased chemicals from C6-sugars, we here report our research activities on the catalytic effect of a wide range of inorganic salts on the conversion of D-glucose in aqueous solutions.

\section{Experimental Section}

\subsection{Chemicals}

The various halide and sulfate salts were obtained from Merck KGaA (Darmstadt, Germany) except for $\mathrm{AlCl}_{3} \cdot 6 \mathrm{H}_{2} \mathrm{O}$ (99\%) and $\mathrm{Fe}_{2}\left(\mathrm{SO}_{4}\right)_{3} \cdot \mathrm{xH}_{2} \mathrm{O}$ (99\%) which were purchased from Sigma-Aldrich, and anhydrous $\mathrm{CrCl}_{2}$ and $\mathrm{LaCl}_{3}$ which were obtained from Acros Organics (Geel, Belgium). D-glucose (99\%), D-fructose (99\%), levulinic acid (98\%), formic acid (98\%) and L-lactic acid (1 M, standardized solution) were purchased from Sigma-Aldrich. Sulfuric acid (95-97\%) and hydrochloric acid (37\%) were obtained from Merck KGaA. DL-glyceraldehyde (95\%) and dihydroxyacetone (98\%) were supplied by Acros Organics (Geel, Belgium). De-ionized water was used to prepare the various solutions. 


\subsection{Experimental Procedures}

The reactions were conducted in glass ampoules with an inside diameter of $3 \mathrm{~mm}$, wall thickness of $1.5 \mathrm{~mm}$ and length of $150 \mathrm{~mm}$. A series of glass ampoules was loaded with $0.5 \mathrm{~mL}$ of an aqueous solution of $0.1 \mathrm{M}$ D-glucose containing a pre-determined amount of the selected inorganic salt and subsequently sealed with a torch. The sealed ampoules were placed in a constant temperature oven. At various reaction times, an ampoule was taken out of the oven and directly quenched in a water bath $\left(20^{\circ} \mathrm{C}\right)$ to stop the reaction. The reaction mixture was taken from the ampoule and the solid particles (humins) were separated from the reaction mixture by centrifugation using a micro centrifuge (Omnilabo International BV) for $15 \mathrm{~min}$ at $1200 \mathrm{rpm}$. The particle-free solution was diluted with de-ionized water and analyzed by HPLC and capillary electrophoresis (CE).

\subsection{Analytical Methods}

The amounts of D-glucose, D-fructose, D-mannose, hydroxymethylfurfural, dihydroxyacetone, DL-glyceraldehyde and levulinic acid in the reaction mixture were quantified using HPLC. The HPLC was equipped with a Hewlett Packard 1050 pump, a Biorad Aminex HPX-87H organic acid column and a Waters 410 refractive index detector. The mobile phase was an aqueous solution of sulfuric acid $(5 \mathrm{mM})$ at flow rate of $0.55 \mathrm{~mL} / \mathrm{min}$. The column was operated at $60{ }^{\circ} \mathrm{C}$. All samples were measured in duplicate.

A capillary electrophoresis (CE) system from Agilent Technologies was used to determine the amount of formic-, acetic-, glycolic- and lactic acid in the reaction mixture. The CE apparatus was equipped with a cassette containing a standard fuse capillary $(75 \mu \mathrm{m}$ i.d., $72 \mathrm{~cm}$ active length, and 80.5 total length) and a diode array detector (DAD). The CE was operated at a temperature of $20{ }^{\circ} \mathrm{C}$ and a voltage of $-25 \mathrm{kV}$. Electropherograms were recorded at $350 \mathrm{~nm}$ with a reference at $200 \mathrm{~nm}$. A buffer solution $(\mathrm{pH}=4.6)$ from Agilent Technologies containing $5 \mathrm{mM}$ cetyltrimethyl-ammonium bromide (CTAB) was used. The capillary was preconditioned prior to each measurement by flushing the buffer solution for 4 min at 1 bar. All samples were measured in duplicate.

An Inolab pH 730 meter equipped with a Sentix 81 probe was used to measure the $\mathrm{pH}$ of the reaction mixtures at room temperature.

\subsection{Definitions}

The conversion of starting material $\left(\mathrm{X}_{\mathrm{i}}\right)$ was calculated using the following equation:
$\mathrm{X}_{\mathrm{i}}=\left(1-\frac{\mathrm{C}_{\mathrm{i}}}{\mathrm{C}_{\mathrm{i}, 0}}\right) \times 100 \mathrm{~mol} \%$

where $C_{i}$ is the concentration of reactant $i$ after a certain reaction time and $\mathrm{C}_{\mathrm{i}, 0}$ denoted the initial concentration of the reactant.

The yield $\left(\mathrm{Y}_{\mathrm{j}}^{\mathrm{C}}\right)$ and selectivity $\left(\mathrm{S}_{\mathrm{j}}^{\mathrm{C}}\right)$ of the reaction products were expressed as carbon-yield and calculated as follows:

$\mathrm{Y}_{\mathrm{j}}^{\mathrm{C}}=\frac{\mathrm{N}_{\mathrm{j}}^{\mathrm{C}}}{\mathrm{N}_{\mathrm{i}}^{\mathrm{C}}} \times \frac{\text { Concentration of product }}{\text { Initial concentration of reactant }} \times 100 \mathrm{C}-\mathrm{mol} \%$

$S_{j}^{C}=\frac{Y_{j}^{C}}{X_{i}} \times 100 \mathrm{C}-\mathrm{mol} \%$

where $\mathrm{N}_{i}^{C}$ and $\mathrm{N}_{j}^{C}$ denote the number of carbon atoms of reactant and product, respectively. The carbon yield was used to compensate for the fact that not all products have a similar carbon number as the starting material D-glucose, following a procedure published by Bicker et al. [19].

\section{Results and Discussion}

\subsection{Effect of Type of Salts on the D-glucose Conversion}

The effect of a wide range of different salts on the reaction of D-glucose in water was screened at $140{ }^{\circ} \mathrm{C}$ using a $0.1 \mathrm{M}$ D-glucose solution and a $5 \mathrm{mM}$ solution of salt as the catalyst. Both halide and sulfate salts of alkali $(\mathrm{Na})$, alkali earth $(\mathrm{Mg})$, aluminum (Al) and transition metals (Mn(II), $\mathrm{Co}(\mathrm{II}), \mathrm{Ni}$ (II), $\mathrm{Fe}(\mathrm{II}), \mathrm{Fe}(\mathrm{III}), \mathrm{La}(\mathrm{III}), \mathrm{Cr}(\mathrm{II})$ and $\mathrm{Zn}(\mathrm{II})$ ) were explored. Sulfuric and hydrochloric acid were used as the reference.

The effect of the presence of salts on the conversion of D-glucose after $6 \mathrm{~h}$ reaction time is shown in Fig. 1. It is clear that all salts catalyse the reaction more efficiently than the Bronsted acids $\mathrm{HCl}$ and $\mathrm{H}_{2} \mathrm{SO}_{4}$ under the prevailing reaction conditions. Iron, alkali and alkali earth salts gave low D-glucose conversions $(<30 \mathrm{~mol} \%)$. Significantly higher conversions were found with transition metals and aluminum salts. Essentially quantitative D-glucose conversions were observed for $\mathrm{Al}(\mathrm{III})$ and Cr(II) salts, whereas $\mathrm{Zn}(\mathrm{II})$ also showed good conversion levels.

No major differences were observed between the halide and sulfate salts of the various metals, suggesting that anion effects in this type of catalysis are of less importance than cation effects. 


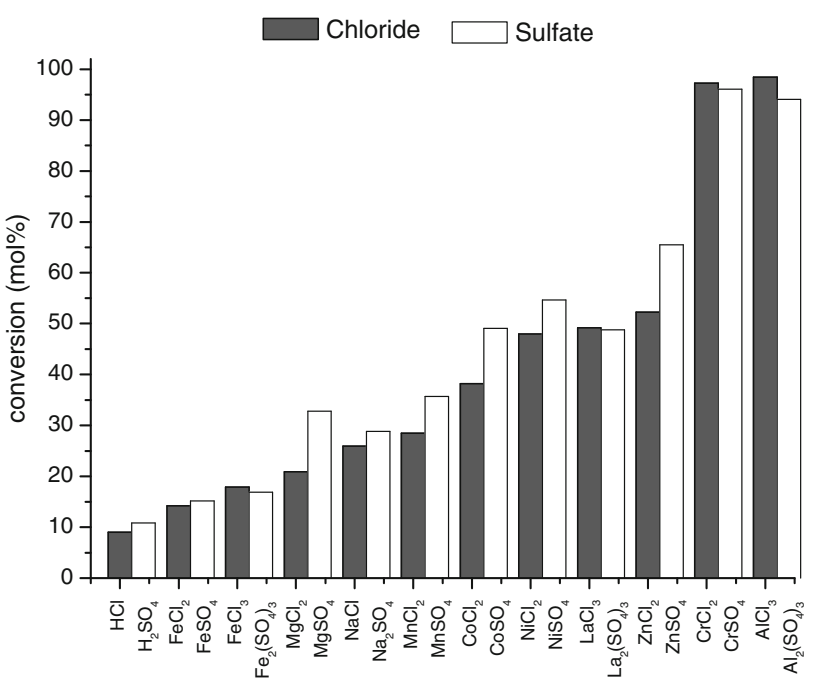

Fig. 1 Effect of various chloride and sulfate salts on the conversion of D-glucose $\left(\mathrm{C}_{\text {salt }}=5 \mathrm{mM}, \mathrm{C}_{\text {acids }}=5 \mathrm{mM}, \mathrm{T}=140{ }^{\circ} \mathrm{C}, t=6 \mathrm{~h}\right)$

\subsection{Effects of salts on the chemo-selectivity} of the reactions

To gain insights in the influence of the type of salts on the chemo-selectivity of the reaction, the liquid products were identified and quantified by HPLC and CE analyses. Table 2 shows the main reaction products for the various salts.

For iron, alkali and alkali earth metals as the catalyst, the formation of D-fructose and trace amounts of HMF and levulinic acid were observed. The main products for the transition metal and aluminum salts were C6-sugars (D-fructose and D-mannose), furanics (HMF) and organic acids (levulinic-, formic-, glycolic-, acetic-, and lactic acid). Besides these components, major amounts of dark brown solids were formed, known as humins. The formation of humins has been reported for acid catalysed C6-sugar conversions and under some conditions may even be the main product. The compounds are known to consist of higher molecular weight materials formed by condensation reactions. Thus we may conclude that the reaction pathways in the presence of salts appear more complicated than when using typical Bronsted acids like sulfuric acid. In the latter case, lactic acid and glycolic acid were not observed and to the best of our knowledge are also not

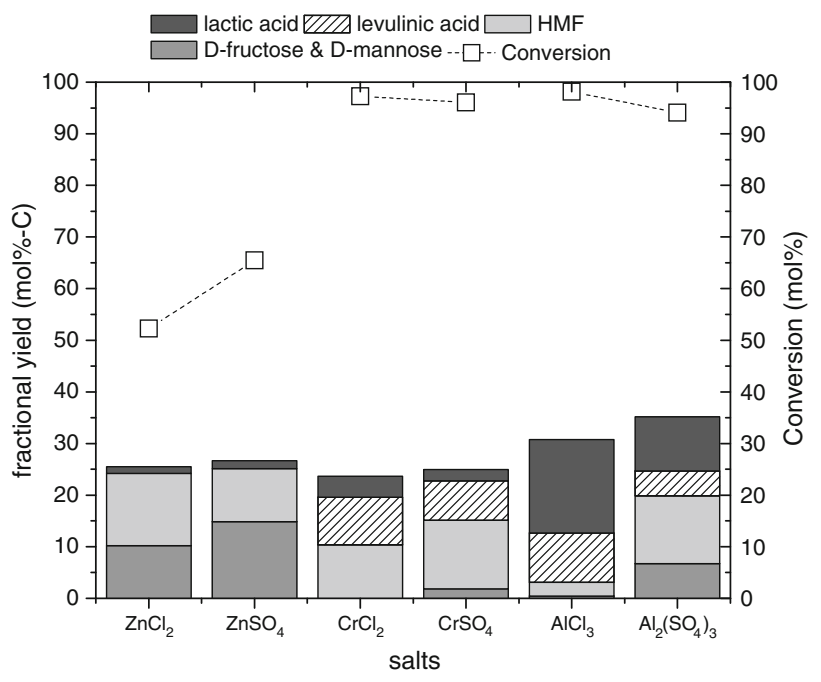

Fig. 2 Product yield after $6 \mathrm{~h}$ reaction time for various salts $\left(\mathrm{C}_{\mathrm{GLC}}=0.1 \mathrm{M}, \mathrm{C}_{\text {salt }}=5 \mathrm{mM}, T=140{ }^{\circ} \mathrm{C}\right)$

reported in the literature when the reactions are carried out at temperatures below $200{ }^{\circ} \mathrm{C}$.

For the three best performing catalysts with respect to D-glucose conversion ( $\mathrm{Zn}(\mathrm{II}), \mathrm{Cr}(\mathrm{II})$ and $\mathrm{Al}(\mathrm{III})$, see Fig. 1), the yields of the various individual products at $6 \mathrm{~h}$ reaction time are given in Fig. 2. Also included are the D-glucose conversions for each run.

Clearly visible is the difference in chemo-selectivity for the three salts. The aluminum salts result in the formation of considerable amounts of lactic acid and this acid is, besides humins, actually the main product when using $\mathrm{AlCl}_{3}$. For Cr-salts, the amount of lactic acid is lower than for Al-salts. However, this comparison is rather difficult to make as the conversion of the intermediate C6-sugars (Dfructose and D-mannose) is not similar for both salts (vide infra). Of interest is the chemo-selectivity for $\mathrm{Zn}$-salts. Lactic acid was present in only very low amounts and the major product was HMF. This implies that $\mathrm{Zn}$-salts may have potential for the synthesis of HMF from C6-sugars.

\subsection{Development of a Reaction Network}

For $\mathrm{AlCl}_{3}$, the composition of the reaction mixtures was followed in time and a typical reaction profile

Table 2 Influence of type of salts on the reaction products

\begin{tabular}{ll}
\hline Type of catalyst & Products \\
\hline Mineral acids & HMF, formic acid and levulinic acid \\
$\mathrm{Fe}(\mathrm{II}), \mathrm{Fe}(\mathrm{III}), \mathrm{Mg}$ and $\mathrm{Na}$ salts & D-fructose, HMF (trace amount), formic acid and levulinic acid \\
$\mathrm{Mn}(\mathrm{II}), \mathrm{Co}(\mathrm{II}), \mathrm{Ni}(\mathrm{II}), \mathrm{La}(\mathrm{III})$, & D-fructose, D-mannose, HMF, formic acid, levulinic acid, \\
$\mathrm{Cr}(\mathrm{II}), \mathrm{Zn}(\mathrm{II})$ and $\mathrm{Al}(\mathrm{III})$ salts & acetic acid, glycolic acid and lactic acid \\
\hline
\end{tabular}


$\left(0.1 \mathrm{M} \mathrm{D}\right.$-glucose, $\left.5 \mathrm{mM} \mathrm{AlCl} 3,140{ }^{\circ} \mathrm{C}\right)$ is depicted in Fig. 3. At the start of the reaction, the formation of D-fructose and D-mannose was observed. However, these are clearly intermediate products as the concentrations show a clear optimum. It is well possible that the salt promotes the isomerisation of D-glucose to D-mannose and $\mathrm{D}$-fructose. This isomerisation reaction is well known to be catalysed by solids (cation ion exchange resins, hydrotalcites and metal oxides such as $\mathrm{ZrO}_{2}$ and $\mathrm{TiO}_{2}$ ) and involves an 1,2-enediol as the intermediate [10, 22-24]. The D-fructose and D-mannose formed in the isomerisation reaction are not inert and also known to react to, among others, HMF and levulinic acid [1].

The main water soluble products are organic acids like lactic acid, formic acid and levulinic acid. Only minor amounts of glycolic acid and acetic acid were formed (Fig. 3b). As for the Bronsted acid catalysed reaction, levulinic acid is likely formed from HMF (Scheme 1). The reaction of $\mathrm{HMF}$ to levulinic acid is known to give formic acid as the co-product (Scheme 1) and the levulinic- and formic acid are expected to be formed in a 1 to 1 molar ratio. In our experiments, the amount of formic acid is slightly higher than that of levulinic acid. We do not yet have a sound explanation for this observation. It is possible that additional formic acid is formed by yet unknown pathways.

Evidence that aqueous $\mathrm{AlCl}_{3}$ solutions catalyse the conversion of HMF to levulinic acid and formic acid comes from a separate experiment. When an aqueous solution of $\mathrm{HMF}(0.1 \mathrm{M})$ and $\mathrm{AlCl}_{3}(5 \mathrm{mM})$ were heated to $180{ }^{\circ} \mathrm{C}$ for $1 \mathrm{~h}, 90 \% \mathrm{HMF}$ conversion was observed and levulinic acid was obtained in $50 \mathrm{~mol} \%$ yield (entry 1, Table 3).

Lactic acid, the main reaction product, is likely formed from the C6-sugars via a complex reaction pathway neither involving HMF nor levulinic acid as intermediates [19, 21]. The first step is believed to consist in the formation of dihydroxyacetone and glyceraldehyde from the C6-sugars in the mixture through a retro-aldol condensation reaction. In a subsequent step these are dehydrated to pyruvaldehyde which subsequently rearranges to lactic acid (Scheme 2).
Recently, the ability of Lewis acids to convert trioses like glyceraldehyde and dihydroxyacetone into lactic acid has been reported. For example, the application of a Sn-beta zeolite as solid Lewis acid in water gave high lactic acid yields $(90 \%)$ for reactions at $125^{\circ} \mathrm{C}$ and $24 \mathrm{~h}$ reaction time [25]. Further evidence for the involvement of glyceraldehyde or dihydroxyacetone in the conversion of C6-sugars to lactic acid under the reaction conditions and salt catalysts employed in this study was obtained by performing reactions with glyceraldehyde and dihydroxyacetone using $\mathrm{AlCl}_{3}$ as the salt catalyst $\left(140{ }^{\circ} \mathrm{C}\right)$. After 90 min reaction time, both are converted to lactic acid in high yields (90\%, entries 2 and 3, Table 3), a clear indication that this reaction is well possible and likely to occur. It also implies that simple salts are efficient catalysts for lactic acid synthesis from glyceraldehyde or dihydroxyacetone.

The presence of $\mathrm{Al}(\mathrm{III})$ ions is essential for the formation of lactic acid. When reacting glyceraldehyde or dihydroxyacetone in the absence of salt catalysts or with Bronsted acids like $\mathrm{HCl}$, lactic acid was not detected and the formation of the isomerisation products (dihydroxyacetone or glyceraldehyde), the dehydration product (pyruvaldehyde) and brown insoluble products were observed (entries 7 and 8, Table 3).

So far, we do not have a sound explanation for the formation of the small amounts of acetic acid and glycolic acid formed in the course of the reaction. Srokol et al. observed the formation of small amounts of glycolic acid and acetic acid when reacting C6-sugars at elevated temperatures $\left(T=350{ }^{\circ} \mathrm{C}\right)$ [26]. The formation of acetic acid and glycolic acid was assumed to proceed via retro-aldol condensation reactions.

On the basis of these experiments we can conclude that aqueous solutions of Al-salts catalyse (1) the isomerisation of D-glucose to D-fructose and D-mannose, (2) the conversion of these sugars to glyceraldehyde and dihydroxyacetone and subsequently to lactic acid and (3) also promote the conversion of the C6-sugars to HMF and subsequently to levulinic acid and formic acid. With Bronsted acids like
Fig. 3 Reaction profile of the conversion of $\mathbf{D}$-glucose using $\mathrm{AlCl}_{3}$ as a catalyst $\left(\mathrm{C}_{\mathrm{GLC}}=0.1 \mathrm{~mol} / \mathrm{l}\right.$, $\mathrm{C}_{\text {salt }}=5 \mathrm{mM}, T=140{ }^{\circ} \mathrm{C}$ )
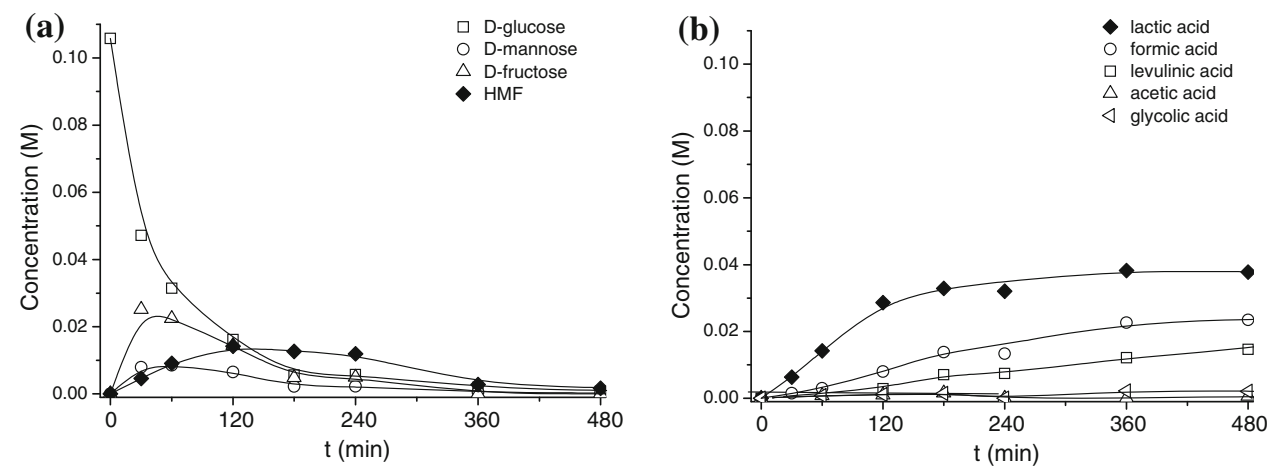
Table 3 Probing the reaction network, experimental data for reactions with intermediate products ${ }^{\mathrm{a}}$

\begin{tabular}{|c|c|c|c|c|c|c|c|}
\hline \multirow[t]{2}{*}{ No } & \multirow[t]{2}{*}{ Starting material } & \multirow[t]{2}{*}{ Catalyst } & \multirow[t]{2}{*}{$\mathrm{t}(\mathrm{min})$} & \multirow[t]{2}{*}{$\mathrm{T}\left({ }^{\circ} \mathrm{C}\right)$} & \multirow[t]{2}{*}{ Conversion $(\mathrm{mol} \%)$} & \multicolumn{2}{|l|}{ Yield (C-mol\%) } \\
\hline & & & & & & Levulinic acid & Lactic acid \\
\hline 1 & $\mathrm{HMF}$ & $\mathrm{AlCl}_{3}$ & 60 & 180 & 90 & 50 & - \\
\hline $2^{\mathrm{b}}$ & DL-glyceraldehyde & $\mathrm{AlCl}_{3}$ & 90 & 140 & 100 & - & 89 \\
\hline $3^{\mathrm{b}}$ & Dihydroxy-acetone & $\mathrm{AlCl}_{3}$ & 90 & 140 & 100 & - & 91 \\
\hline $4^{\mathrm{b}}$ & DL-glyceraldehyde & $\mathrm{AlCl}_{3}$ & 40 & 140 & 100 & - & $78(21)^{\mathrm{c}}$ \\
\hline $5^{\mathrm{b}}$ & Dihydroxy-acetone & $\mathrm{AlCl}_{3}$ & 40 & 140 & 80 & - & 76 \\
\hline $6^{\mathrm{b}}$ & Dihydroxy-acetone & $\mathrm{ZnCl}_{2}$ & 40 & 140 & 43 & - & 6 \\
\hline $7^{\mathrm{d}}$ & Dihydroxy-acetone & $\mathrm{HCl}$ & 40 & 140 & 68 & - & - \\
\hline $8^{d}$ & Dihydroxy-acetone & No catalyst & 40 & 140 & 21 & - & - \\
\hline
\end{tabular}

${ }^{a}$ Catalyst concentration was always $5 \mathrm{mM}$, substrate concentration always $0.1 \mathrm{M}$

${ }^{\mathrm{b}}$ Clear solution after reaction was observed

c Yield in parentheses is the C-mol\% yield of dihydroxyacetone

${ }^{\mathrm{d}}$ Pyruvaldehyde and insoluble brown solids were observed

Scheme 2 Simplified reaction network to explain the product formation for D-glucose in the presence of inorganic salts

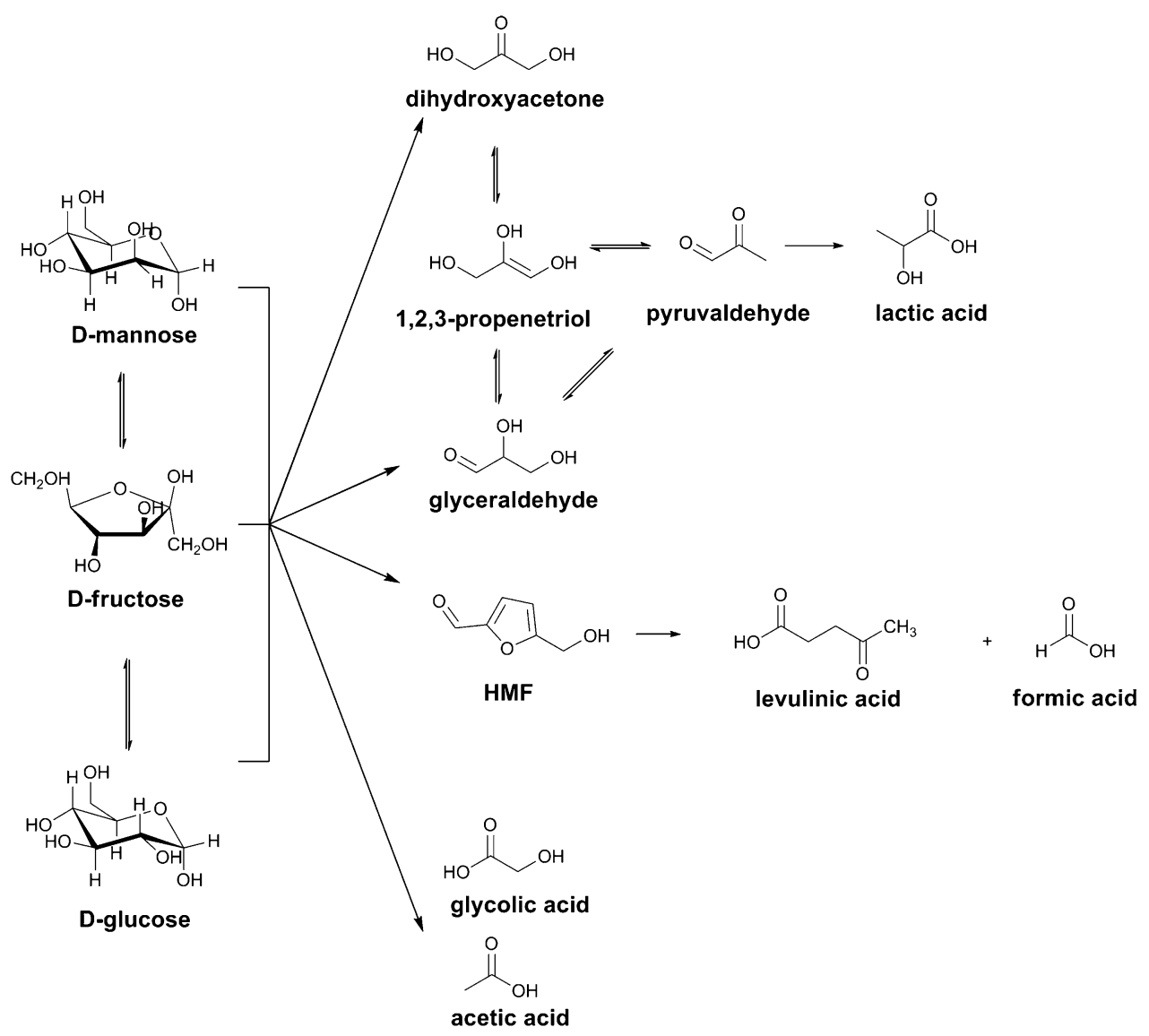

$\mathrm{HCl}$ and $\mathrm{H}_{2} \mathrm{SO}_{4}$, the pathway leading to lactic acid has not been observed at temperatures below $200{ }^{\circ} \mathrm{C}$ and the pathway to HMF/levulinic acid is dominant.

The catalytic action of the inorganic salts used in this study likely involves the Lewis acidic metal centers. The question arises whether Bronsted acidity also plays a role as most salts are amphoteric and when dissolved in water affect the $\mathrm{pH}$. For instance, the $\mathrm{pH}$ of the Al-solutions at room temperature $\left(\mathrm{AlCl}_{3}: 3.86, \mathrm{Al}_{2}\left(\mathrm{SO}_{4}\right)_{3}: 4.33\right)$ was far below 7 , indicating that Bronsted acidity may also play a role. However, the observed high reactivity as well as the change in chemo-selectivity when using salt solutions in comparison with Bronsted acids alone clearly implies that the metal ions play a key role. 


\section{Conclusions}

The catalytic effects of inorganic salts on the conversion of D-glucose in water have been explored in a systematic manner under similar process conditions. $\mathrm{Zn}(\mathrm{II}), \mathrm{Cr}(\mathrm{II})$ and $\mathrm{Al}(\mathrm{III})$ are the most active salts under the conditions employed and the activity exceeds mineral acids like $\mathrm{HCl}$ and sulfuric acid. The major liquid product for the Al-salts is lactic acid, an interesting biobased chemical, which is not observed when using Bronsted acids at temperatures below $200{ }^{\circ} \mathrm{C}$. For $\mathrm{Zn}(\mathrm{II})$, the major product is HMF under the conditions employed. Further kinetic studies at a range of conditions will be required to optimize the lactic acid and HMF yields for both salts and these are currently in progress. On the basis of the experimental findings, a reaction network is proposed to explain the product compositions. Individual reactions in the network were investigated to determine their validity. An interesting observation was that the intermediate trioses like glyceraldehyde and dihydroxyacetone may be converted in high yields to lactic acid when using Al-salts, an unprecedented finding with possible application potential.

Acknowledgements C. B. Rasrendra thanks the University of Groningen for financial support in the form of a Bernoulli Scholarship to perform his $\mathrm{PhD}$ study.

Open Access This article is distributed under the terms of the Creative Commons Attribution Noncommercial License which permits any noncommercial use, distribution, and reproduction in any medium, provided the original author(s) and source are credited.

\section{References}

1. Corma A, Iborra S, Velty A (2007) Chem Rev 107:2411

2. Werpy T, Petersen G (eds) (2004) Top value added chemicals from biomass. National Renewable Energy Lab, Golden
3. Girisuta B, Janssen LPBM, Heeres HJ (2006) Chem Eng Res Des $84: 339$

4. Bozell JJ, Moens L, Elliott DC, Wang Y, Neuenscwander GG, Fitzpatrick SW, Bilski RJ, Jarnefeld JL (2000) Resour Conserv Recycl 28:227

5. Binder JB, Raines RT (2009) JACS 131:1979

6. Zhao HB, Holladay JE, Brown H, Zhang ZC (2007) Science 316:1597

7. Su Y, Brown HM, Huang X, Zhou X-d, Amonette JE, Zhang ZC (2009) Appl Catal A 361:117

8. Heeres H, Handana R, Chunai D, Rasrendra CB, Girisuta B, Heeres HJ (2009) Green Chem 11:1247

9. Takeuchi Y, Jin FM, Tohji K, Enomoto H (2008) J Mater Sci 43:2472

10. Lourvanij K, Rorrer GL (1997) J Chem Technol Biotechnol 69:35

11. Van Dam HE, Kieboom APG, Van Bekkum H (1986) StarchStarke 38:95

12. Tyrlik SK, Szerszen D, Kurzak B, Bal K (1995) Starch-Starke 47:171

13. Tyrlik SK, Szerszen D, Olejnik M, Danikiewicz W (1996) J Mol Catal A 106:223

14. Seri K, Inoue Y, Ishida H (2001) Bull Chem Soc Jpn 74:1145

15. Seri K, Inoue Y, Ishida H (2000) Chem Lett 29:22

16. Krupenskii VI (1981) Izv Vuz Khim Kh Tekh 24:1081

17. Krupenskii VI (1983) Koksnes Kimija 2:86

18. Krupenskii VI, Korolkov II, Dolgaya TV (1977) J Appl Chem USSR 50:1281

19. Bicker M, Endres S, Ott L, Vogel H (2005) J Mol Catal A 239:151

20. Kong L, Li G, Wang H, He W, Ling F (2008) J Chem Technol Biotechnol 83:383

21. Yan X, Jin F, Tohji K, Moriya T, Enomoto H (2007) J Mater Sci 42:9995

22. Moreau C, Durand R, Roux A, Tichit D (2000) Appl Catal A 193:257

23. Watanabe M, Aizawa Y, Iida T, Nishimura R, Inomata H (2005) Appl Catal A 295:150

24. Angyal SJ (2001) In: Stütz AE (ed) Glycoscience: epimerisation, isomerisation and rearrangement reactions of carbohydrates, vol 215. Springer-Verlag, Berlin, p 1

25. Taarning E, Saravanamurugan S, Holm MS, Xiong JM, West RM, Christensen CH (2009) ChemSusChem 2:625

26. Srokol Z, Bouche AG, van Estrik A, Strik RCJ, Maschmeyer T, Peters JA (2004) Carbohydr Res 339:1717 